\title{
Research on Dynamic Crack Propagation Characteristics of V-shaped Energy-accumulating Charge Pack at Different Angles
}

haohao luo ( 1964423767@qq.com )

China University of Mining and Technology

\section{Yuantong Zhang}

China University of Mining and Technology Beijing Campus

Chengxiao Li

China University of Mining and Technology Beijing Campus

Bin Xu

China University of Mining and Technology Beijing Campus

\section{Research Article}

Keywords: V-shaped energy-accumulating charge, Dynamic caustics, Fractal dimension, V-shaped energy gathering angle

Posted Date: January 18th, 2022

DOI: https://doi.org/10.21203/rs.3.rs-1225656/v1

License: (c) (i) This work is licensed under a Creative Commons Attribution 4.0 International License. Read Full License 


\title{
Research on Dynamic Crack Propagation Characteristics of V-shaped Energy-accumulating Charge Pack at Different
}

\author{
Angles \\ Haohao Luo ${ }^{1}$, Yuantong Zhang , Chengxiao Li ${ }^{1}$, Bin $\mathrm{Xu}^{1}$, \\ 1. School of Mechanics and Civil Engineering, China University of Mining and Technology \\ (Beijing), Beijing 100083, China

\begin{abstract}
In order to study the crack propagation characteristics of the V-shaped energy-storage package at different angles, a new numerical laser caustics test system was used to observe the fracture process of the V-shaped energy-concentrating charge package, the mechanical distribution mechanism around the blast hole of the energy-accumulating charge package is analyzed, and using fractal theory to evaluate the damage degree of the energy-accumulating medicine package. Series of caustics test results show, the main crack has a longer expansion length in the energyconcentrating direction, and the crack expansion length is shorter in the non-energy-concentrating direction, the fractal results of the shaped charge pack show that as the angle of the shaped charge pack increases, the fractal dimension of the binarized picture of the shaped charge pack gradually becomes smaller, and the crack propagation complexity becomes lower and lower, and the main crack is along the energy gathering direction The directivity is becoming less and less obvious, When the energy gathering angle is $120^{\circ}$, the main crack propagation process is similar to that of the circular charge (control group).
\end{abstract}

Key words: V-shaped energy-accumulating charge, Dynamic caustics, Fractal dimension, V-shaped energy gathering angle

\section{Introduction}

In the process of roadway excavation, it is difficult to effectively control the propagation direction of the surrounding blasthole cracks, and it is impossible to eliminate the damage of the surrounding blastholes to the surrounding rock of the roadway, causing over-under-excavation, resulting in waste of a large amount of shotcrete and supporting materials, and affecting the efficiency of roadway excavation. Increasing construction costs, and the use of directional fracture controlled blasting in the peripheral eye can solve the above problems. At present, there are two methods commonly used for directional fracture control. One is to set small diameter holes on both sides of the blast hole, or to artificially create defects in the medium and other technical measures, so as to achieve the purpose of concentration of explosive energy in the fracture direction, so as to realize the directional fracture[1]; the other is to use the energy-concentrating charge or to use the energy-concentrated cutting or slotting shell on the drug roll sleeve.

The detonation products of ordinary blasting scattered randomly around the blasthole, and the resulting cracks expanded randomly. And energy blasting uses the cavitation effect to change the result of the charge to make the detonation products accumulate in a specific direction, which improves the destructive effect in a specific direction. A lot of engineering practice and research 
show that the effect of shaped energy blasting is affected by factors such as stress environment, surrounding rock properties, explosive type, packing quality and initiation method.

For coal seams with high gas content and low air permeability, Mu Chaomin [2] uses shaped energy blasting to achieve fracturing and anti-reflection. Yaoyin [3] used the BGSSC (BilateralGroove-Slot Shaped Charge) method to study the subtle-level timing effects of double-hole delay blasting. Hu et al. [4] adopted BCTE (Bilateral cumulative tensile explosion), which was applied in the sub-pillarless sublevel caving method. Wu et al. [5] used acoustic emission technology to study the influence of different notch angles $\left(45^{\circ}, 60^{\circ}, 90^{\circ}, 120^{\circ}, 135^{\circ}\right)$ on crack propagation, and the notch angle and the degree of fracture were negatively correlated. Yang et al. [6] used dynamic caustics to study the crack propagation characteristics of the slit charge under high ground stress conditions. Fan's research results show that the shaped charge structure has a significant effect on the direction of explosive energy propagation [7]. Xie et al. [8 9] studied the expansion of blasting cracks under confining pressure, and the confining pressure has a certain influence on the development of blasting cracks. Gong Min et al. [10] studied the blasting technology to improve gas drainage. Wu et al. [11] studied the formation factors and crack propagation mechanism of elliptical bilinear jets. Ding et al. [12] studied the superposition effect of stress waves between two holes and the mechanism of mechanical expansion. Different from chemical explosions, some scholars [13 14] use electric explosions instead of chemical explosions. The advantages of electric explosions are safety, high efficiency, and no need for chemical explosives.

Some scholars [15 17] studied peripheral directional fracture controlled blasting, which reduced the number of peripheral holes and over-under-excavation. B. Mohanty [18] studied the characteristics of the blasting strain wave distribution at the V-shaped energy accumulation, and proposed to set up control holes on both sides of the blast hole to realize the crack propagation direction. Y. Nakamura et al. [19] used a high-speed camera to study the crack growth characteristics under the condition of the control hole with or without energy accumulation. The difference between the energy gathering blasting in this article and the above is that the energy gathering blasting direction in this article is different from the above documents. The energy gathering hole direction in the above documents is an inner $\mathrm{V}$ shape, and the energy gathering hole direction in this article is V-shaped outside.

The above-mentioned documents are mostly considered from the engineering application angle of energy-accumulating blasting, and there are few studies on the angle of the V-shaped energyaccumulating groove. In this paper, a dynamic caustics test system is used to study the angle of the V-shaped energy-concentrating groove, and using fractal theory to calculate the binary image of burst cracks, a circular blasthole is set as a control group to study the angle of the V-shaped energyconcentrating groove Influence on the dynamic propagation characteristics of blasting cracks.

\section{Mechanical analysis of shaped charge}

Under the action of the explosion shock wave, the effective stress Von Mise of any point in the rock mass is [20]:

$$
\sigma_{i}=\frac{1}{\sqrt{2}}\left[\left(\sigma_{r}-\sigma_{\theta}\right)^{2}+\left(\sigma_{\theta}-\sigma_{z}\right)^{2}+\left(\sigma_{z}-\sigma_{r}\right)^{2}\right]^{\frac{1}{2}}
$$


Where: $\sigma_{i}$ is the stress intensity at any point; $\sigma_{r}, \sigma_{\theta}$ is the radial stress and the tangential stress respectively; $\sigma_{z}$ is the vertical stress.

With the blast hole as the center, the explosive propagates outward from around the blast hole. At this time, the stress at any point of the rock mass is expressed as:

$$
\begin{gathered}
\sigma_{r}=p r^{\prime-\alpha} \\
\sigma_{\theta}=-b \sigma_{r} \\
\sigma_{z}=\mu_{d}\left(\sigma_{r}+\sigma_{\theta}\right)=\mu_{d}(1-b) \sigma_{r}
\end{gathered}
$$

Where: $r^{\prime}$ is the specific distance, $r^{\prime}=r / r_{b}, r$ is the distance from the point to the center of the charge, $\alpha$ is the shock wave attenuation coefficient, $\mu_{d}$ is the dynamic Poisson's ratio of the coal and rock mass, $b$ and is the lateral pressure coefficient.

Shock wave pressure around the blasthole is $p$ :

$$
\begin{aligned}
& p=\frac{p_{0} k^{-2 \gamma}}{2} l_{e} n \\
& p_{0}=\frac{1}{1+\gamma} \rho_{0} D^{2}
\end{aligned}
$$

Where: $p_{0}$ is the explosive detonation pressure, $\rho_{0}$ is the explosive density, $D$ is the explosive velocity, $\gamma$ is the expansion adiabatic index of the detonation product, $k$ is the radial charge non-coupling coefficient, $l_{e}$ is the charge axial coefficient, $n$ is the pressure increase coefficient around the blast hole, generally $n=10$.

\section{Test system and test method}

\subsection{Test system}

The test adopts a new digital laser dynamic caustic line method test system. The test system is mainly composed of a laser, a beam expander, a field lens and a high-speed camera. In the experiment, the shooting frequency of the high-speed camera is $100000 \mathrm{fps}$, between two adjacent photos The time interval is 10us. First, the laser a emits a monochromatic light color, passes through the beam expander $b$ to form divergent light, and forms parallel light through the field lens I $c$. The parallel light passes through the test piece $d$, and the field lens II e condenses the parallel light onto the high-speed camera $\mathrm{f}$, The information collected by the high-speed camera $\mathrm{f}$ is transmitted to the computer g, and the start signal is sent to the high-speed camera $g$ and the explosive in the test piece 
$d$ through the synchronization controller $i$, the new digital laser caustics test system is shown in Figure 1.

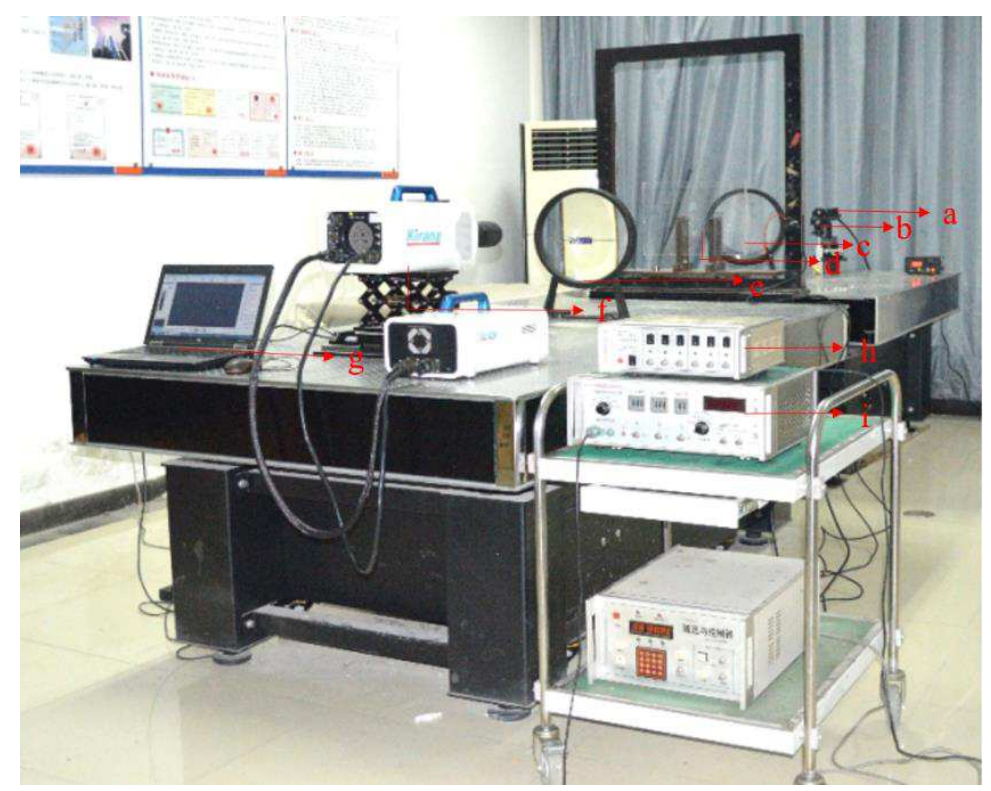

(a.Laser device b. beam expander. c. field lens I d. specimen. e. field lens II. f. high-speed camera. g. computer. h. explosive initiating device. i. synchronous control device)

Figure 1 the digital laser dynamic caustics experimental system

\subsection{Test principle}

The test is based on the transmission dynamic caustics method. By observing the shape of the crack tip caustic speckle, the instantaneous stress state of the crack tip can be obtained, and the dynamic stress intensity factor value of the propagating crack tip can be accurately obtained. The calculation formula of the dynamic stress intensity factor at the crack tip is [21]:

$$
\begin{gathered}
K_{\mathrm{I}}=\frac{2 \sqrt{2 \pi} F(v)}{3 z_{0} d c g^{5 / 2}} D_{\max }^{5 / 2} \\
K_{\mathrm{II}}=\mu K_{\mathrm{I}}^{\mathrm{d}}
\end{gathered}
$$

In the formula: $D_{\max }$ is the maximum diameter of the focal speckle at the crack tip, $z_{0}$ is the distance from the reference plane to the test piece, and the value is $z_{0}=1 \mathrm{~m}$, and $d$ is the thickness of the test piece, which $d$ is $150 \mathrm{~mm}, F(v)$ is the adjustment factor under dynamic load, $F(v)=1, \quad c$ is the optical constant, $c=1.08 \times 10-10 \mathrm{~m}^{2} / \mathrm{N}, g$ is the numerical factor, and $g$ $=3.17, \mu$ is the ratio of the stress intensity factor. It can be seen that, for a particular test, $K_{\mathrm{I}}$ is determined by the maximum radius $D_{\max }$ of the focal speckle, and $K_{\mathrm{II}}$ is determined by both $\mu$ and $K_{\mathrm{I}}$.

The center of the caustic spot is the position of the crack tip, so the caustic spot position at each instant can be obtained from the caustic photos taken by the high-speed camera, because the time interval between two adjacent caustic photos is very short ( $7.14 \mu \mathrm{s})$, the average crack speed of two adjacent photos can be regarded as the instantaneous speed of crack propagation at that moment. 
The calculation formula of the instantaneous crack velocity is [22]:

$$
\begin{aligned}
v_{i}(t) & =1 / 2\left[\frac{l_{i+1}(t+\Delta t)-l_{i}(t)}{\Delta t}+\frac{l_{i}(t)-l_{i-1}(t-\Delta t)}{\Delta t}\right] \\
& =\frac{\sqrt{\left(x_{i+1}-x_{i}\right)^{2}+\left(y_{i+1}-y_{i}\right)^{2}}+\sqrt{\left(x_{i}-x_{i-1}\right)^{2}+\left(y_{i}-y_{i-1}\right)^{2}}}{2 \Delta t}
\end{aligned}
$$

In the formula: $v$ is the instantaneous velocity of the crack; $\Delta s$ is the displacement value of the crack tip of adjacent caustics photos, $\Delta t$ is the time difference between adjacent caustics photos, and $\Delta t=7.14 \mathrm{us}$.

\subsection{Specimen description}

The test uses plexiglass as the material, and it has passed that the plexiglass has dynamic fracture characteristics similar to brittle rock. The mechanical parameters of plexiglass are: longitudinal wave velocity $\mathrm{C}_{\mathrm{p}}=2320 \mathrm{~m} / \mathrm{s}$, shear wave velocity $C_{s}=1260 \mathrm{~m} / \mathrm{s}$, dynamic elastic modulus ed $E_{d}=6.1 \mathrm{GN} / \mathrm{m} 2$, Poisson's ratio $V_{d}=0.31$.

The size of the test piece is a plexiglass plate with a size of $400 * 400 * 3 \mathrm{~mm}$, the energy gathering hole is located in the center of the plexiglass plate, the angle of the V-shaped energy gathering groove is set to $30^{\circ}, 60^{\circ}, 90^{\circ}$ and $120^{\circ}$, and the energy gathering medicine package The partial enlarged view is shown in Fig. 2. The diameter of the drug bag is $6 \mathrm{~mm}$, the packaged charge of shaped charge is $60 \mathrm{mg}$, and the type of explosive is lead azide.

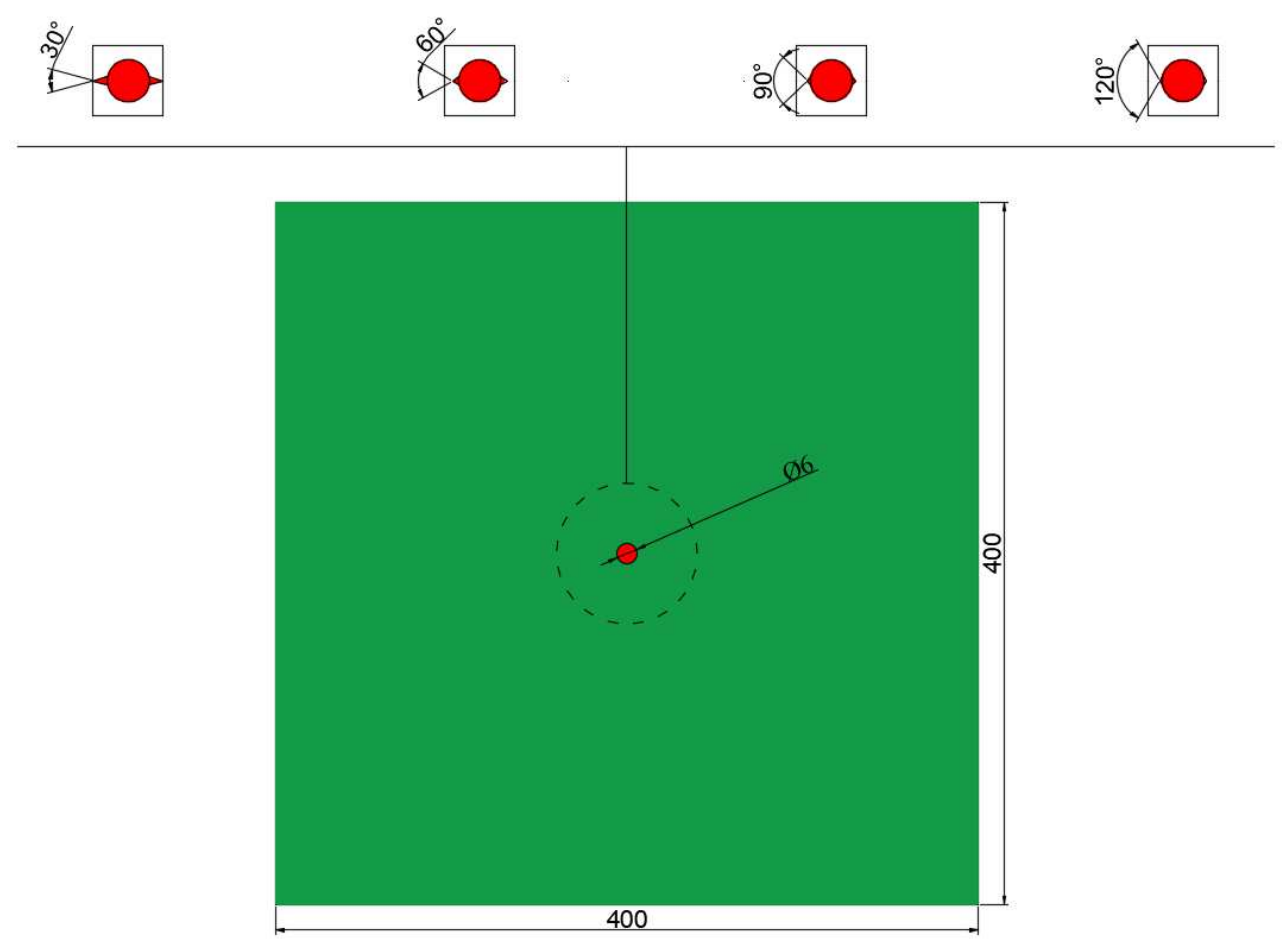

Figure 2 Schematic diagram of energy-generating medicine packaged medicine from different angles 


\section{Dynamic caustics test results and analysis}

\subsection{Series of caustics images}
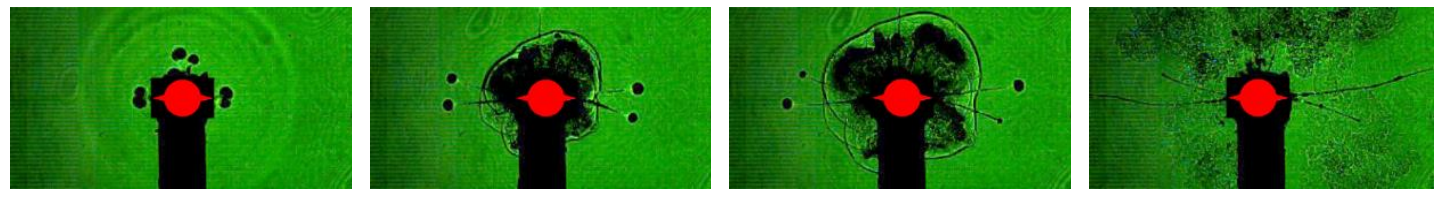

a. $30^{\circ} \mathrm{V}$-shaped Energy-accumulating charge
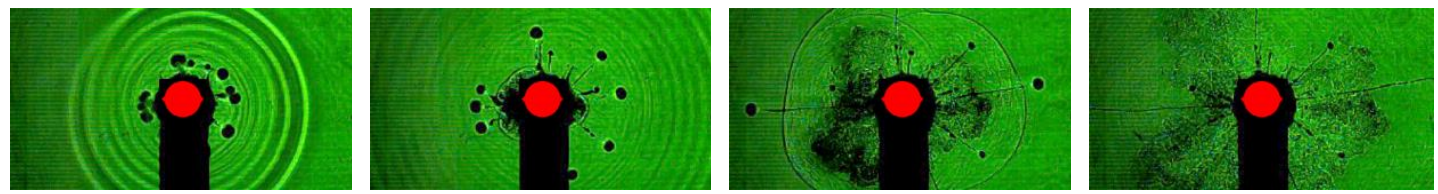

b. $60^{\circ} \mathrm{V}$-shaped Energy-accumulating charge
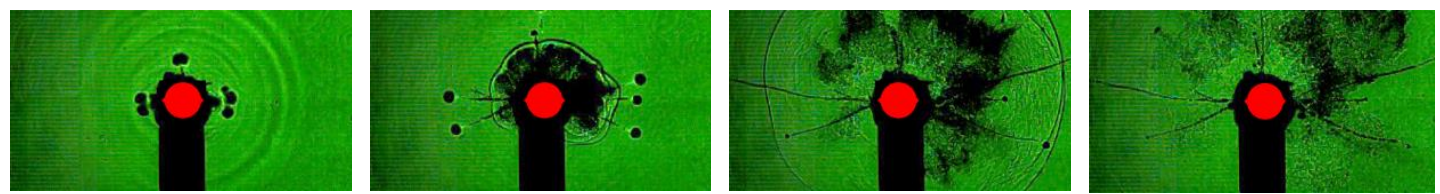

c. $90^{\circ} \mathrm{V}$-shaped Energy-accumulating charge
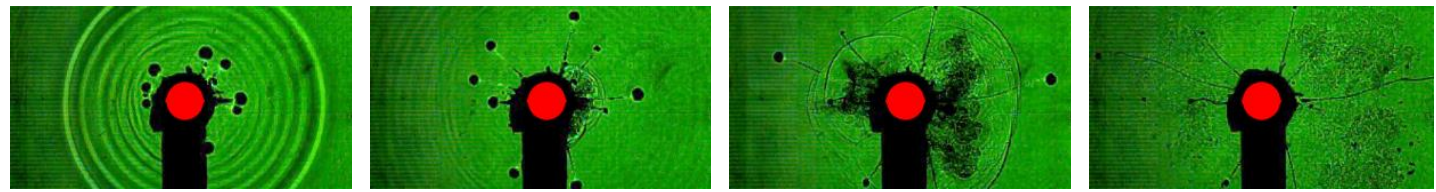

d. $120^{\circ} \mathrm{V}$-shaped Energy-accumulating Charge
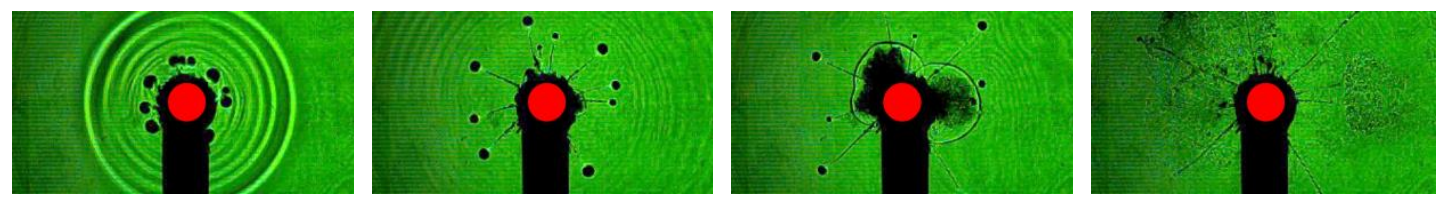

e. Round charge (Control group)

Figure 3 Caustics of different angles of energy-accumulating bag series

A series of focal speckle photos under the explosion of the shaped charge pack are shown in Figure 3. After the shaped charge pack explodes, under the action of the explosive shock wave, a crushing zone is formed around the blast hole, and then the shock wave of the explosion decays into a compression stress wave, the explosive stress wave is smaller than the dynamic compressive strength of plexiglass, and the cracks begin to develop and expand under the combined action of tensile and compressive stress. With the accumulation of energy, the radius of the focal speckle keeps increasing. Due to the energy accumulation of the explosive in the energy gathering direction, cracks develop fastest in the energy gathering direction, and the crack expansion length is longer. In the non-energy-concentrating direction, the crack is the first to stop and the crack propagation length is shorter. 


\subsection{Analysis of crack propagation characteristics}

Figure 4 shows the time history curve of the stress intensity factor at the tip of the main crack at different energy gathering angles. The main crack along the energy gathering direction begins to crack under the action of the explosive shock wave. After the main crack cracks, the stress intensity factor at the crack tip keeps changing. Then, due to the effect of explosive gas, the stress intensity factor at the tip of the main crack rises sharply, and then gradually decays. The difference is that with the increase of the energy accumulation angle, the stress intensity factor of the main crack tip of the $30^{\circ}, 60^{\circ}, 90^{\circ}, 120^{\circ}$ energy accumulation package also gradually decreases.

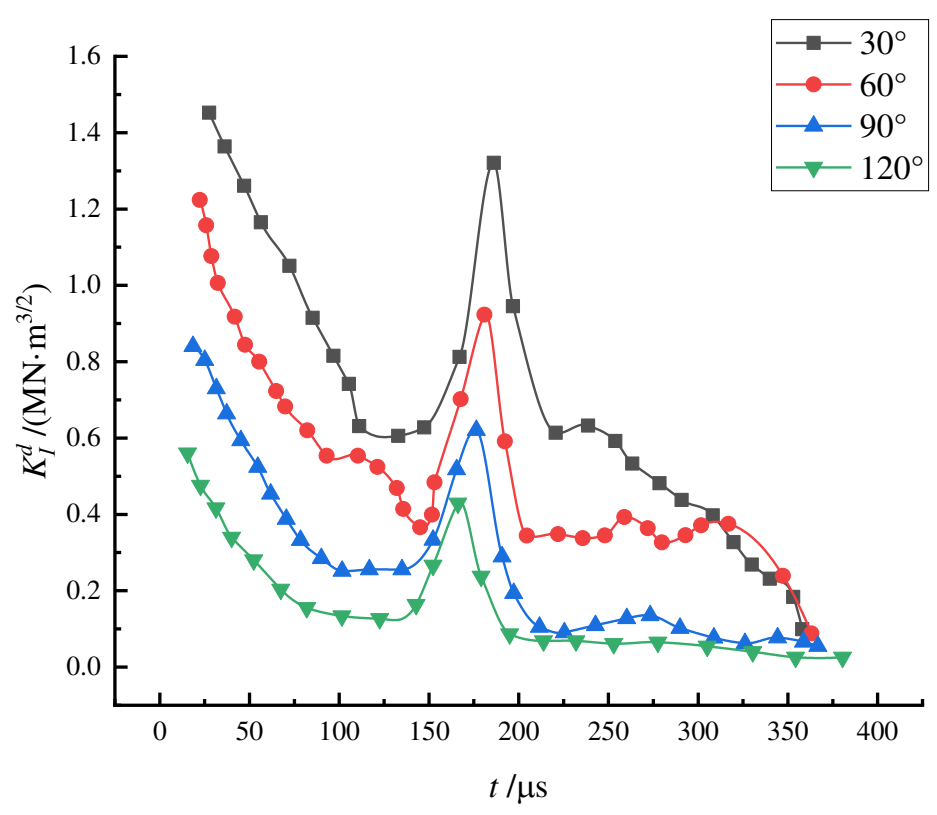

Fig. 4 Time history curve of stress intensity factor at crack tip

Figure 5 shows the time history curve of the main crack growth rate at different energy gathering angles. The general trend of the growth rate of the main crack is as follows: After the main crack cracks, the crack growth rate decreases, the detonation gas lags behind the explosion shock wave, and the detonation gas uses the "gas wedge" to push the main crack growth speed up sharply, and then the crack tip When the tensile stress is less than the dynamic tensile strength of the material, the crack stops growing. It is worth noting that as the energy gathering angle increases, the overall growth rate of the main crack decreases. This is because as the energy gathering angle increases, the stress concentration phenomenon at the energy gathering tip becomes less and less obvious, which makes it more and more difficult for the main crack to detonate along the energy gathering direction. 


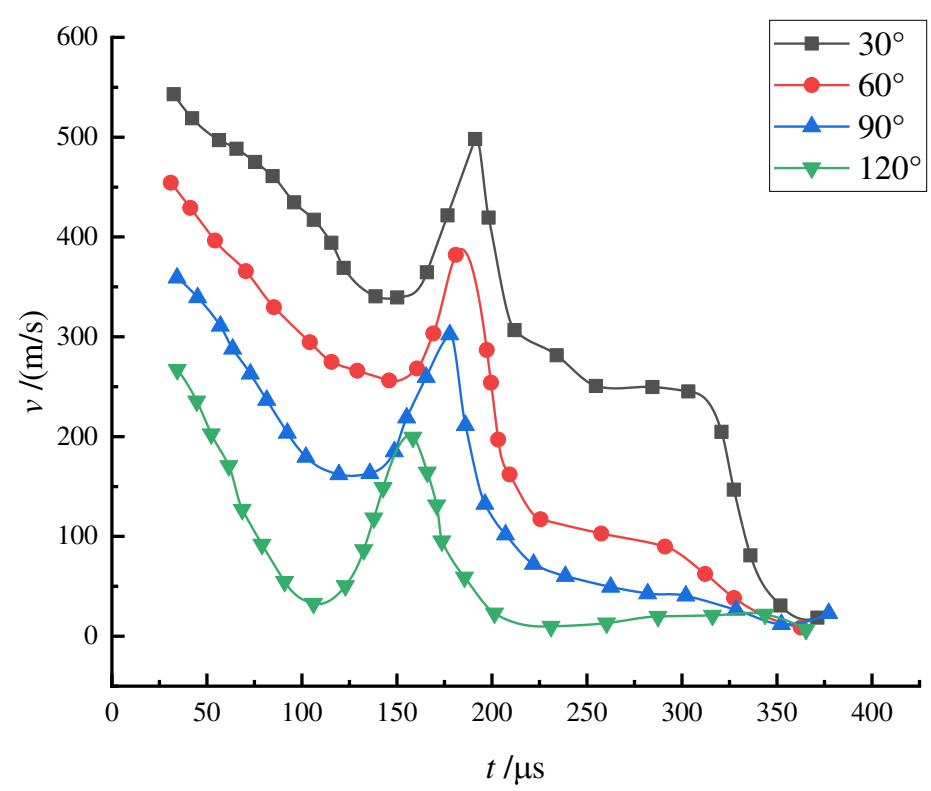

Fig. 5 Time history curve of crack tip growth velocity

\section{Fractal results of crack propagation in shaped charge}

\subsection{Fractal principle}

According to the idea of the box dimension algorithm, combined with the image analysis technology and the Matlab calculation function, the calculation method based on the Matlab digital image box dimension is written. The picture pixels are processed to the integer power of 2 . In this experiment, the picture pixels are $1024 * 1024$. The picture is binarized, and the processed binarized picture is imported into the matlab program for operation.

The damage evolution process of the rock conforms to the fractal characteristics. Therefore, the initial micro-cracks and cracks in the rock are continuously activated and evolve into a process of macroscopic cracks, the box covering method can be used to calculate the fractal dimension of each area after blasting, take the box with side length $\delta$ to cover the image, some of the boxes are empty, and the rest of the boxes cover part of the fractal. Count the number of all non-empty boxes and continuously reduce the side length $\delta$ of the box. When $\delta \rightarrow 0$, we can get [23]:

$$
\begin{gathered}
D=-\lim _{\delta \rightarrow 0} \frac{\lg N(\delta)}{\lg \delta}=\lim _{\varepsilon \rightarrow 0} \frac{\lg N(\delta)}{\lg (1 / \delta)} \\
\lg N(\delta)=D \lg \delta+b
\end{gathered}
$$

In the actual calculation process, a box with side length $\delta$ is selected, and after a series of changes $(\lg \delta, \lg N(\delta)$ ), perform a linear fit to the two, find the slope between the two by the least square method, and the slope is the fractal dimension $\mathrm{D}$. 


\subsection{Analysis of fractal results}
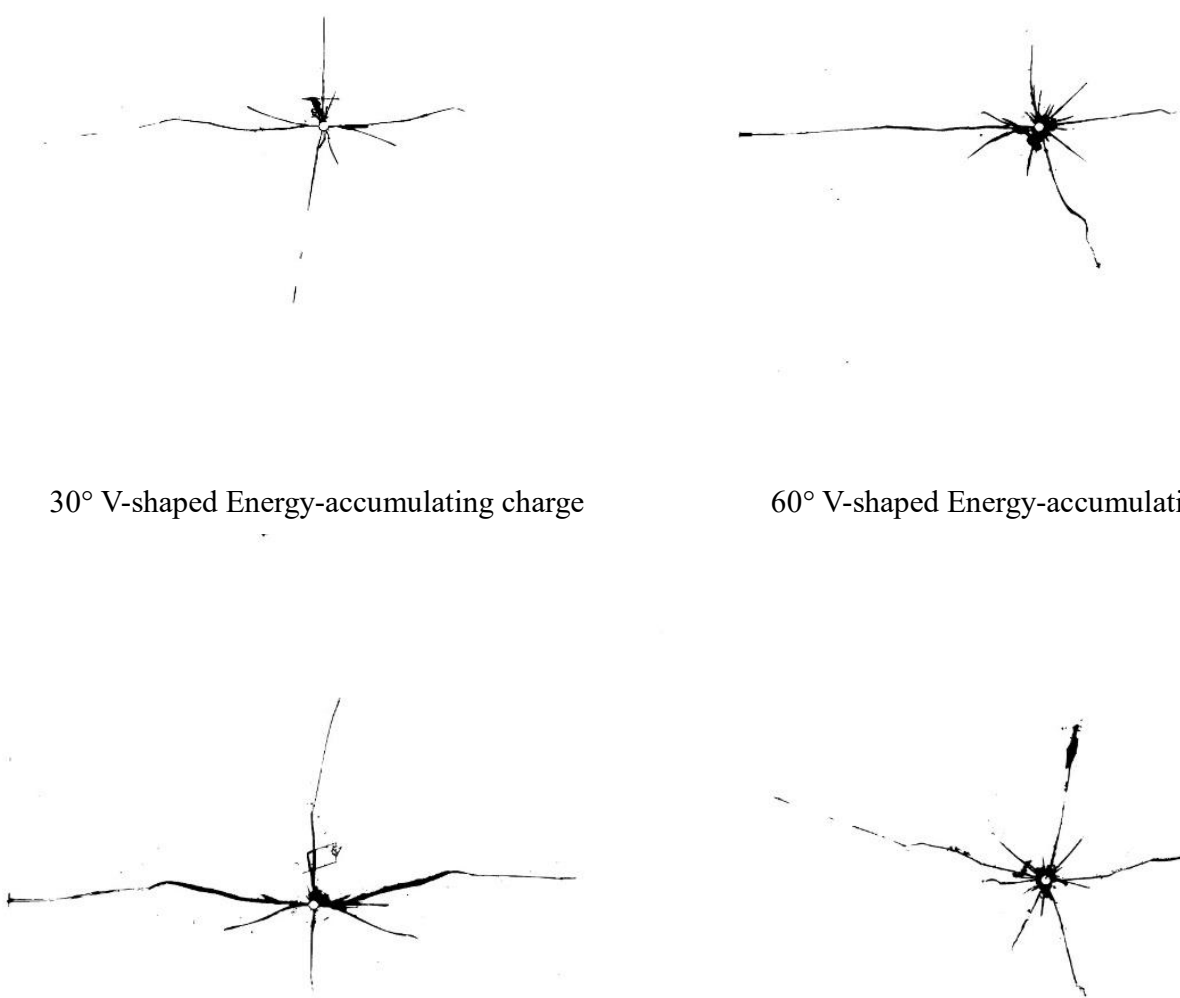

$60^{\circ} \mathrm{V}$-shaped Energy-accumulating charge
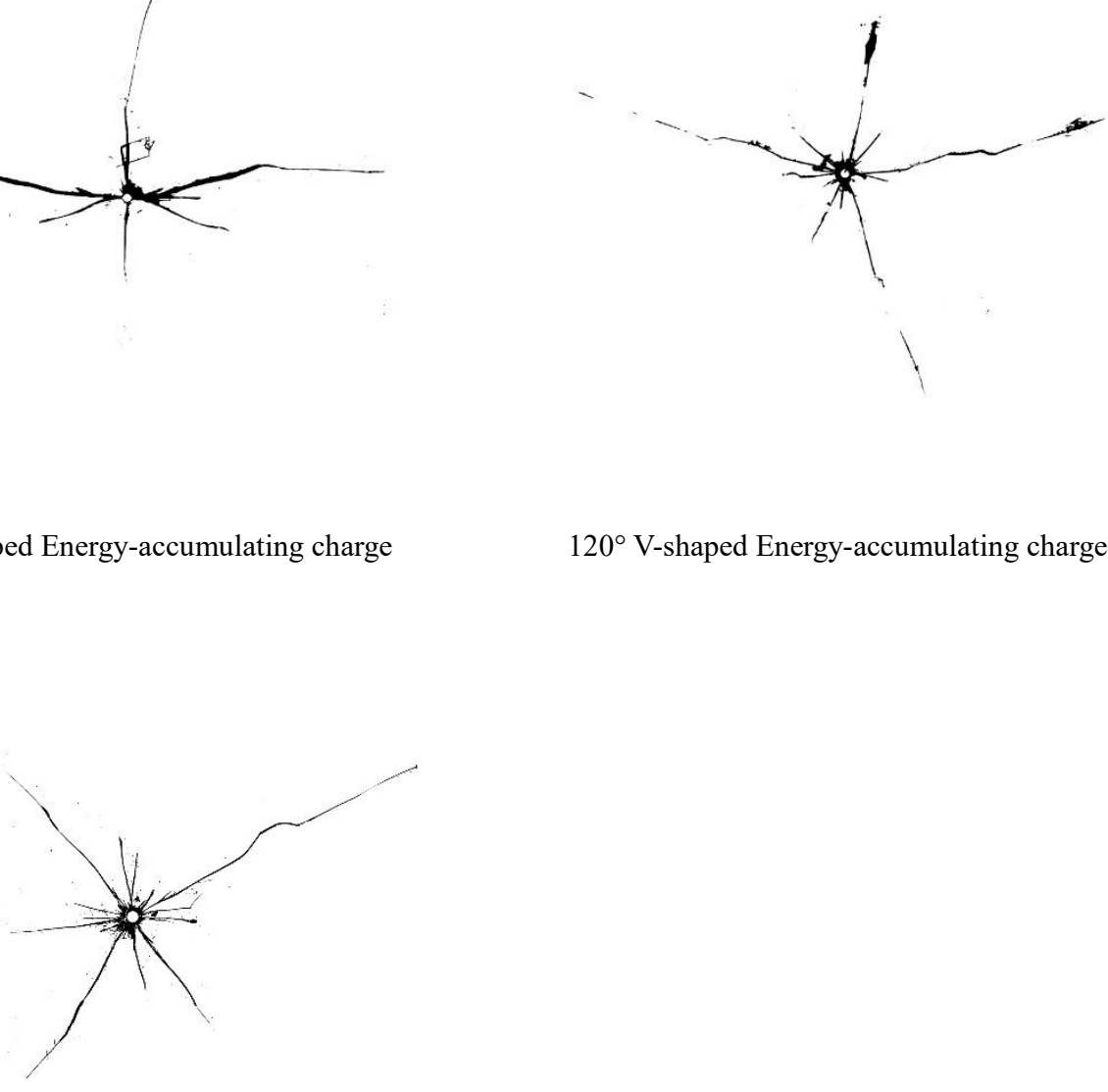
Round charge (Control group)

图 6 Fig. 6 Binarization diagram of crack initiation of V-shaped energy-accumulating charge package at different angles

It can be seen from Figures 7-8 that the fractal dimensions of burst lines at $30^{\circ}, 60^{\circ}, 90^{\circ}$, and $120^{\circ}$ are $1.2498,1.2647,1.3206,1.3340$, respectively. The fractal dimensions of burst lines in the circular charge control group Is 1.3379 . This shows that with the increase of the energy gathering angle, the fractal dimension of the energy gathering hole burst crack pattern gradually increases, and the crack propagation degree becomes more and more complicated and disordered. Among them, the ordinary circular blasthole has the largest fractal dimension, and the crack propagation degree is the most re-explosive and disordered. The main crack propagation direction of $30^{\circ}, 60^{\circ}$, and $90^{\circ}$ shaped energy blasting is basically the same as that of energy accumulation, and the main crack propagation direction of $120^{\circ}$ shaped energy blasting starts to deviate from the energy accumulation direction.

This is because, in the case of a certain energy gathering width, as the energy gathering angle increases, the energy gathering area gradually becomes smaller (as shown in Figure 2), and less blasting gas enters the energy gathering, which is not conducive to cracks. Further expansion, as the energy gathering angle is $120^{\circ}$, the expansion direction of the main crack begins to deviate from the energy gathering direction. The circular blasthole acts as a control group, and there is no focused energy setting, and the main crack direction of the blasthole shows disorder and randomness.

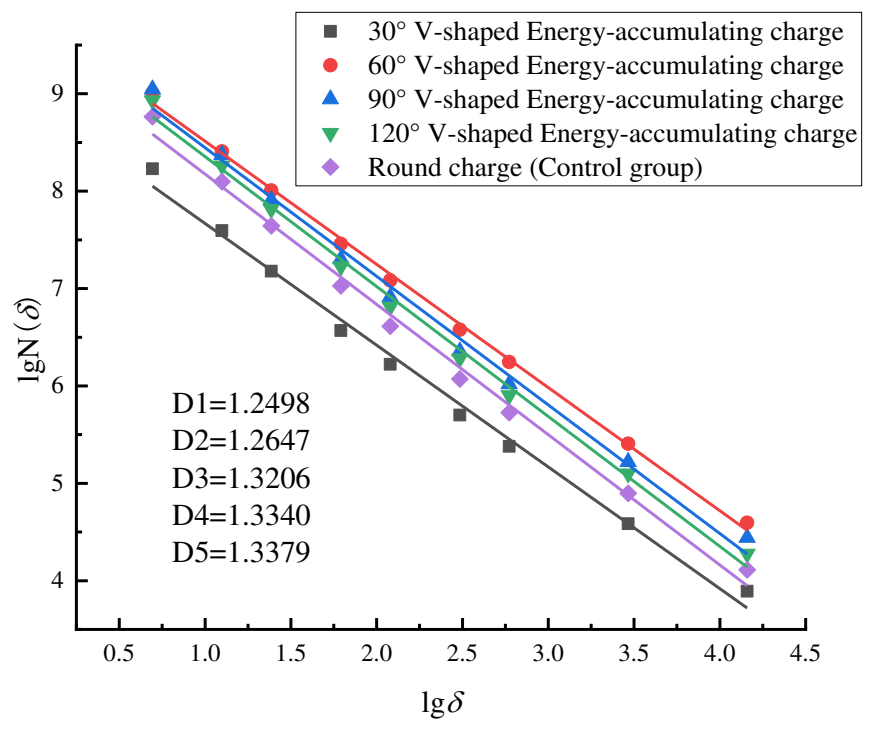

Fig. 7 Straight line fitting of the box dimension of burst crack 


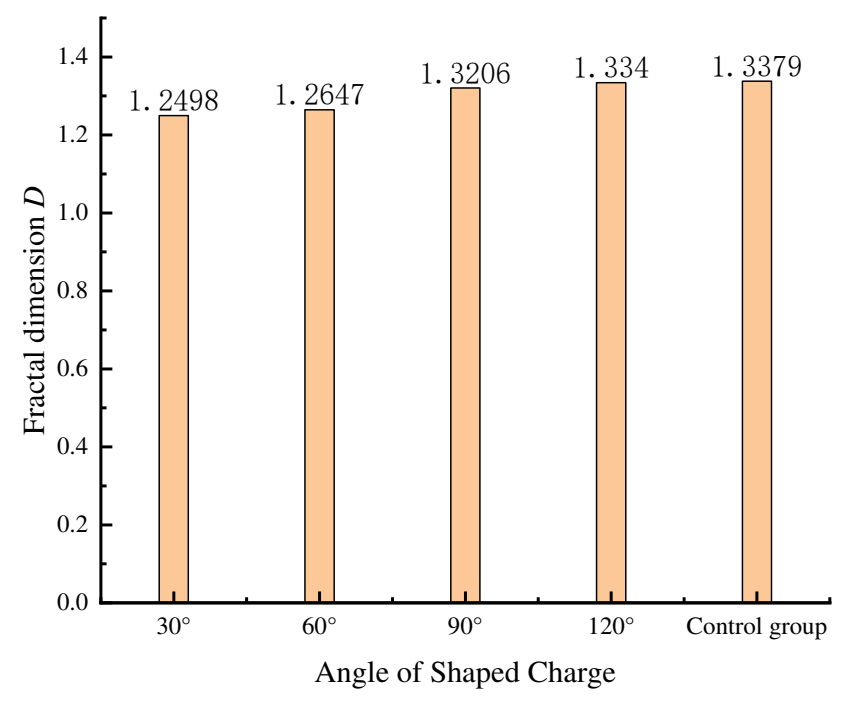

Figure 8 The relationship between the fractal dimension of the V-shaped energy-accumulation package and the angle

6 Numerical simulation study of " $V$ " shaped energy-accumulating medicine package

Explosives are described by the JWL equation of state, which can accurately describe the pressure, volume, and energy characteristics of the explosive during the explosion process. The model uses MAT_HIGH_EXPLOSIVE_BURN, combined with the JWL state equation, to simulate the relationship between pressure and volume during explosive explosion[24], the basic parameters of explosives and plexiglass are shown in Table 1 and Table 2.

$$
P=A\left(1-\frac{\omega}{R_{1} V}\right) e^{-R_{1} V}+B\left(1-\frac{\omega}{R_{2} V}\right) e^{-R_{2} V}+\frac{\omega E_{0}}{V}
$$

In the above formula, $P$ is the detonation pressure; $V$ is the relative volume; $E_{0}$ is the internal energy per unit volume; $\omega, A, B, R_{1}, R_{2}$ are parameters related to explosive materials.

Table 1 Basic parameters of explosives

\begin{tabular}{lllllllll}
\hline $\begin{array}{l}\text { Density } \\
/\left(\mathrm{g} / \mathrm{cm}^{3}\right)\end{array}$ & $\begin{array}{l}\text { Detonation } \\
\text { velocity } /(\mathrm{m} / \mathrm{s})\end{array}$ & $\begin{array}{l}\text { Detonation } \\
\text { pressure } / \mathrm{GPa}\end{array}$ & $\mathrm{A} / \mathrm{GPa}$ & $\mathrm{B} / \mathrm{GPa}$ & $\mathrm{R} 1$ & $\mathrm{R} 2$ & $\omega$ & $\begin{array}{l}\mathrm{E}_{0} / \\
\left(\mathrm{kJ} / \mathrm{cm}^{3}\right)\end{array}$ \\
3.83 & 5110 & 5.33 & 1524 & 11.44 & 5.75 & 1.53 & 0.21 & 5.84 \\
\hline
\end{tabular}

表 2 有机玻璃力学参数

\begin{tabular}{lllll}
\hline Density $/\left(\mathrm{g} / \mathrm{cm}^{3}\right)$ & $\begin{array}{l}\text { Compressive } \\
\text { strength } / \mathrm{MPa}\end{array}$ & $\begin{array}{l}\text { Shear modulus } \\
/ \mathrm{GPa}\end{array}$ & Poisson's ratio & $\begin{array}{l}\text { Elastic Modulus } \\
/ \mathrm{GPa}\end{array}$ \\
\hline 1180 & 84 & 30.3 & 0.32 & 6.1 \\
\hline
\end{tabular}




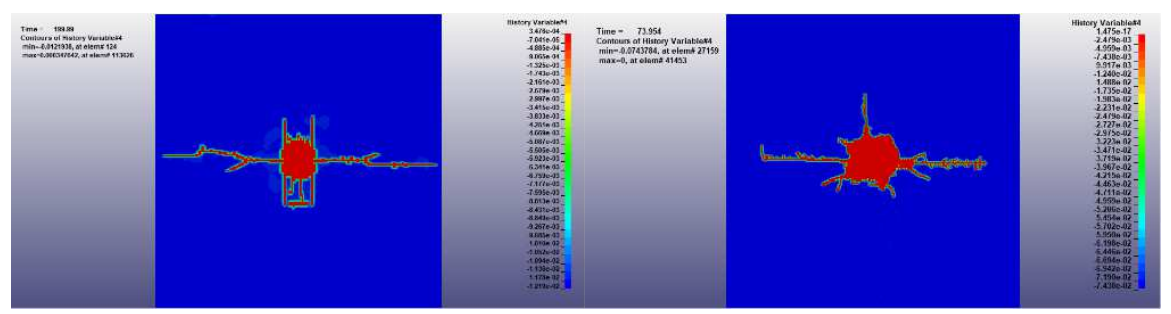

$30^{\circ} \mathrm{V}$-shaped energy-accumulating charge $60^{\circ} \mathrm{V}$-shaped energy-accumulating charge

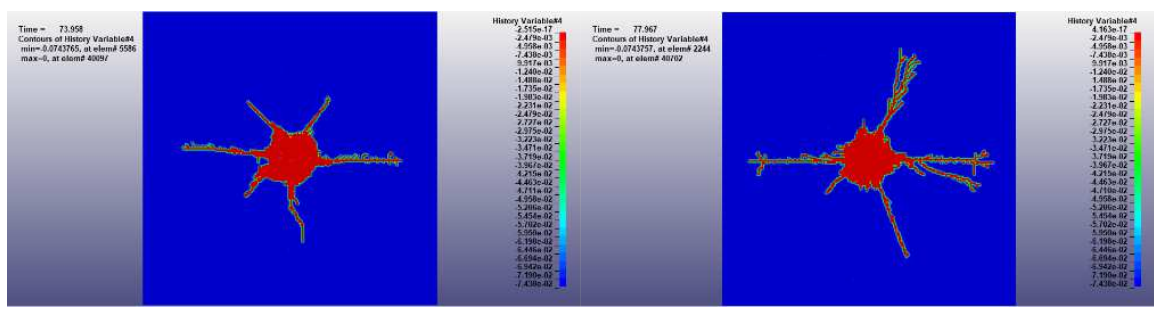

$90^{\circ} \mathrm{V}$-shaped energy-accumulating charge $120^{\circ} \mathrm{V}$-shaped energy-accumulating charge

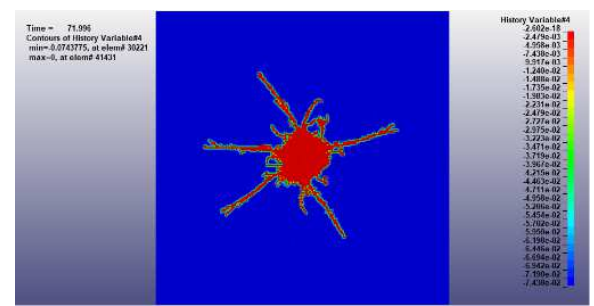

Round charge (Control group)

Fig. 9 Explosion crack propagation diagram of different V-shaped energy-accumulating charges

It can be seen from Figure 9 that after the explosive exploded, the blast hole was the center of the circle to form a crushing zone. Under the combined action of the explosive shock wave and the explosive gas, the crack further expanded forward. The crack propagation in the direction perpendicular to the energy accumulation direction is shorter; the crushing area of the $60^{\circ}$ energyaccumulating cartridge is enlarged, the main crack propagation length along the energy accumulation direction is reduced, and the crack expansion length in the vertical energy accumulation direction is increased; The energy accumulation effect of $90^{\circ}$ and $120^{\circ}$ shaped charge packs in the energy accumulation direction is gradually not obvious, but the main crack in the energy accumulation direction still exists; the crack growth pattern of the round charge pack is used as a control group, and the main crack growth direction shows randomness, Evenly distributed along the circumference of the blast hole. The main crack growth pattern of the energy-accumulating powder package in the numerical simulation is basically the same as that of the main crack in the explosion experiment.

7 conclusion

(1) The crack propagation length of the V-shaped energy-accumulating cartridge is longer in the energy-concentrating direction, and the crack propagation length is shorter in the non-energyconcentrating direction, and the crack arrest time in the non-energy-concentrating direction is earlier.

(2) With the increase of the angle of the V-shaped energy-accumulating package, the fractal dimension of the picture after binarization becomes larger and the energy-accumulating effect becomes less and less obvious. This is due to the fact that the V-shaped groove has a certain width. The larger the angle, the smaller the area of the $\mathrm{V}$-shaped groove, which leads to less and 
less obvious "gas wedge" effect of explosive gas. The main crack growth pattern of the $120^{\circ} \mathrm{V}$ shaped charge pack gradually approached the main crack growth pattern of the round charge pack.

(3) The fractal dimension of the burst cracks of the V-shaped energy-accumulating charge is smaller than that of the circular charge, and the orientation of the main crack of the V-shaped energyaccumulating charge is obvious, along the direction of energy accumulation. The main crack propagation of the circular charge has the characteristics of randomness and disorder.

(4) With the increase of the energy-gathering angle of the V-shaped charge bag, the energygathering effect in the energy-gathering direction is gradually insignificant. The main crack propagation direction of the circular charge bag in the control group is randomly distributed. This phenomenon exists in both the explosion test and the numerical simulation.

\section{references}

[1] Liang WM, Yang XL, Yu YQ, Wang JX (2006) Research on theory on directional fracture controlled blasting. Journal of Liaoning Technical University 03:15-16.

[2] Mu CM, Wang HL, Huang WY, Kuang CJ (2013) Increasing permeability mechanism using directional cumulative blasting in coal seams with high concentration of gas and low permeability. Rock and Soil Mechanics 34(09):2496-2500.

[3] Yao Y, Sun Q, Zou BP, Mu QY (2021) Numerical Study on an Innovative Shaped Charge Approach of Rock Blasting and the Timing Sequence Effect in Microsecond Magnitude. Rock Mechanics and Rock Engineering 54(9):4523-4542

[4] Hu JZ, Zhang XY, Gao YB, Ma ZM, Xu XZ, Zhang XP (2019) Directional presplit blasting in an innovative no-pillar mining approach. Journal of Geophysics and Engineering 16(5):875-893.

[5] Wu SJ, Zhai C, Xu JZ, Qin L, Sun Y, Dong RW (2019) The performance of soundless cracking agents for weakening rock roof under different notch angles. Arabian Journal of Geosciences, 2019, 12(11):1-13

[6] Yang RS, Ding CX, Li YL, Yang LY, Zhao Y (2019) Crack propagation behavior in slit charge blasting under high static stress conditions. International Journal of Rock Mechanics and Mining Sciences 119:117-123.

[7] Fan HF, Li SF (2017) A Peridynamics-SPH modeling and simulation of blast fragmentation of soil under buried explosive loads. 318:349-381

[8] Xie LX, Lu WB, Zhang QB, Jiang QH, Wang GH, Zhao J (2016) Damage evolution mechanisms of rock in deep tunnels induced by cut blasting. Tunnelling \& Underground Space Technology Incorporating Trenchless Technology Research 58:257-270

[9] Xie LX, Lu WB, Zhang QB, Jiang QH, Chen, Zhao J (2017) Analysis of damage mechanisms and optimization of cut blasting design under high in-situ stresses. Tunnelling \& Underground Space Technology 66:19-33

[10] Gong M, Liu WB, Wang DS, Wu HR, Chen TM, Qiu DC (2006) Controlled blasting technique to improve gas pre-drainage effect in a coal mine. Journal of University of Science and Technology Beijing 2006,28(03):223-226

[11] Wu B, Wei H, Xu SX, Meng GW, Li HL (2021) Analysis of the Cracking Mechanism of an Elliptical Bipolar Linear-Shaped Charge Blasting. Advances in Civil Engineering 12:1-12

[12] Ding CX, Yang RS, F C (2021) Stress wave superposition effect and crack initiation mechanism 
between two adjacent boreholes. International Journal of Rock Mechanics and Mining Sciences 138(11): 104622

[13] Andres U (1989) Parameters of disintegration of rock by electrical pulses. Powder Technology 58( 4):265-269

[14] Lisitsyn, IV, Inoue, H, Nishizawa, I, Katsuki, S, Akiyama, H (1998) Breakdown and destruction of heterogeneous solid dielectrics by high voltage pulses. Journal of Applied Physics, 84(11), 62626267.

[15] Yong, L, Shen, Z (2006). Study on orientation fracture blasting with shaped charge in rock. Journal of University of Science and Technology Beijing(English Edition) 13(3):193-198

[16] Yang, L, Huang, C, Bao, S, Zhang, L (2020). Model experimental study on controlled blasting of slit charge in deep rock mass. Soil Dynamics and Earthquake Engineering, 138, 106318.

[17] Li, Q, Gao, Z. H, Xu, W. L, Wang, K, Hu, Y (2020) Experimental research on the dynamic propagation process of mode I cracks in the rock under directional fracture blasting using the strain gauge method. Engineering Fracture Mechanics, 235, 107113.

[18] Mohanty, B. (1990). Explosion generated fractures in rock and rock-like materials. Engineering Fracture Mechanics, 35(4), 889-898.

[19] Nakamura, Y, Cho, S. H, Yoneoka, M, Yamamoto, M, Kaneko, K (2004) Model experiments on crack propagation between two charge holes in blasting. Science and Technology of Energetic Materials, 65(2), 34-39.

[20] Dai J (2001) Calculation of radius of the broken and cracked areas in rock by a long charge explosion. Journal of Liaoning Technical University (Natural Science) ,2001(02):144-147

[21] Beinert, J, Kalthoff, J. F.(1981) Experimental determination of dynamic stress intensity factors by shadow patterns. Springer Netherlands. Netherlands: Springe,1981: 281-330.

[22] Qiu, P, Yue, ZW, Yang, RS (2021) Experimental study on mode-I and mixed-mode crack propagation under tangentially incident $\mathrm{p}$ waves, $\mathrm{s}$ waves and reflected waves in blasts. Engineering Fracture Mechanics, 247(12), 107664.

[23] Ding, CX, Yang, RS, Lei, Z, Wang M, Zhao Y, Lin, H (2020). Fractal damage and crack propagation in decoupled charge blasting. Soil Dynamics and Earthquake Engineering, 141, 106503. [24] Qu SJ, Liu JF (2015) Numerical analysis of joint angle effect on cracking with presplit blasting. Rock and Soil Mechanics, 015,36(01):189-194+204. 